Pacific Journal of Mathematic 


\section{BOUNDARY VALUE PROBLEMS FOR PARTIAL FUNCTIONAL DIFFERENTIAL EQUATIONS}

SAMUel M. RANKIN, III

Sufficient conditions are given to ensure the existence of solutions for the boundary value problem

$$
\begin{array}{r}
y(t)=T(t) \phi(0)+\int_{0}^{t} T(t-s) F\left(y_{s}\right) d s \quad 0 \leqq t \leqq b \\
\text { (*) } \quad M y_{0}+N y_{b}=\psi, \quad \psi \in C(=C([-r, 0] ; B) \text { by def. }) .
\end{array}
$$

It is assumed that $T(t), t \geqq 0$, is a strongly continuous semigroup of bounded linear operators on the Banach space $B$ and $T(t), t \geqq 0$, has infinitesimal generator $A$. The function $F$ is continuous from $C$ to $B$ and $M$ and $N$ are bounded linear operators defined on $C$.

Denote by $C$ the Banach space of continuous functions from $[-r, 0]$ into the Banach space $B$, where for each $\varphi \in C,\|\varphi\|_{C}=$ $\sup _{-r \leqq 0 \leq 0} \sup \|\varphi(\theta)\|$. Let $A$ be the infinitesimal generator of a strongly continuous semigroup of linear operators $T(t), t \geqq 0$ mapping $B$ into $B$ and satisfying $|T(t)| \leqq e^{\omega t}$ for some real $\omega$. We let $F$ be a nonlinear continuous function from $C$ into $B$. If $y(t)$ is a continuous function from $[0, T]$ to $B$ for some $T>0$, define the element $y_{t} \in C$ by $y_{t}(\theta)=y(t+\theta)$. Throughout this paper the reference $y(t)$ is a solution of Equation (1) $\left(^{*}\right)$ will mean $y(t)$ satisfies Equation (1) and the boundary condition $\left(^{*}\right)$. The statement $y(\varphi)(t)$ is a solution of Equation (1) will mean $y(t)$ satisfies Equation (1) and the initial condition $y_{0}=\varphi$. The notation Equation (1) without $\left(^{*}\right)$ will always denote the initial value problem.

In a recent paper [8] $\mathrm{C}$. Travis and $\mathrm{G}$. Webb have considered initial value problems for Equation (1). With $F$ satisfying

$$
\|F(\varphi)-F(\bar{\varphi})\| \leqq L\|\varphi-\bar{\varphi}\|_{C}
$$

for some $L>0$ and $\varphi, \bar{\varphi} \in C$, Travis and Webb obtain the existence of unique solutions of Equation (1) for each $\varphi \in C$. In another paper W. E. Fitzgibbon [2] has shown that global solutions of Equation (1) exist if $F$ satisfies for each $\varphi \in C$

$$
\|F(\varphi)\| \leqq K_{1}\|\varphi\|_{C}+K_{2} \text { for some } K_{1}, K_{2} \in R,
$$

and if $T(t), t>0$ is compact.

When Equation (1) has unique solutions for each $\varphi \in C$, the mapping $U(t) \varphi=y_{t}(\varphi)$ is well defined for each $t \geqq 0$ and $\varphi \in C$. Here $y_{t}(\varphi)$ represents the element of $C$ such that $y(\varphi)(t)$ is a solution of 
Equation (1). If $F$ satisfies (2) the following estimate from [8] is true:

$$
\|U(t) \varphi-U(t) \bar{\varphi}\|_{c} \leqq e^{(\omega+L) t}\|\varphi-\bar{\varphi}\|_{c} \quad \text { if } \quad \omega \geqq 0
$$

for all $t \geqq 0$. Throughout this paper it will be assumed that $\omega \geqq 0$.

If $F$ satisfies (3), then we have for each $\varphi \in C$ and $0 \leqq t \leqq b$

$$
\begin{aligned}
\|U(t) \varphi\|_{c} & =\left\|y_{t}(\varphi)\right\|_{c}=\sup _{-r \leq \theta \leq 0}\left\|T(t+\theta) \varphi(0)+\int_{0}^{t+\theta} T(t+\theta-s) F\left(y_{s}\right) d s\right\| \\
& \leqq e^{\omega t}\|\varphi\|_{c}+e^{\omega t} \int_{0}^{t} e^{-\omega s} K_{1}\left\|y_{s}(\varphi)\right\|_{c}+K_{2} d s .
\end{aligned}
$$

This implies that

$$
\left\|y_{t}(\varphi)\right\|_{c} \leqq \bar{K}_{1}\|\varphi\|_{C}+\bar{K}_{2}
$$

where $\bar{K}_{1}=e^{\left(\omega+K_{1}\right) b}$ and $\bar{K}_{2}=e^{\left(\omega+K_{1}\right) b} K_{2} b$.

It is shown in [8] that if the semigroup $T(t), t \geqq 0$ is compact for $t>0$, then the solution mapping $U(t) \varphi=y_{t}(\varphi)$ is compact in $\varphi$ for each fixed $t>r$.

Equation (1) is the integrated form of the functional differential equation

$$
\begin{aligned}
& y^{\prime}(t)=A y(t)+F\left(y_{t}\right) \quad 0 \leqq t \leqq b \\
& y_{0}=\varphi
\end{aligned}
$$

Our results then can be applied to partial functional differential equations of the form

$$
\begin{array}{ll}
v\left({ }_{t} x, t\right)=v_{x x}(x, t)+f(v(x, t-r)) & 0 \leqq t \leqq b, 0 \leqq x \leqq l \\
v(0, t)=v(l, t)=0 & t \geqq 0 \\
\alpha(x, t) v(x, t)+\beta(x, t) v(x, b+t)=\psi(x, t) & -r \leqq t \leqq 0,0 \leqq x \leqq l .
\end{array}
$$

Boundary value problems of the type Equation (6) $\left(^{*}\right)$ have been studied recently by $R$. Fennell and P. Waltman [1], G. Reddien and G. Webb [7] and P. Waltman and J. S. W. Wong [9] when $B=R^{n}$. The work here extends results found in [7] and [9] to Equation (1) $\left({ }^{*}\right)$ when $B$ is infinite dimensional. Certain technical difficulties arise when $B$ is infinite dimensional. For example, the solution mapping $U(t) \varphi$ for Equation (1) is not compact as is the case when $B=R^{n}$, see J. Hale [4]; this is a problem when trying to apply standard fixed point theorems. This difficulty is overcome by assuming the semigroup $T(t), t \geqq 0$ is compact for $t>0$. It will become clear that our results depend on the operators $M$ and $N$, the Lipschitz constant $L$, and the length of the interval $b$. 
Define $S(b) \varphi=x_{b}(\varphi) ; x_{b}(\varphi)$ is the element of $C$ such that $x(\varphi)(t)$ is the unique solution of the system

$$
\begin{array}{ll}
x(t)=T(t) \varphi(0) & t \geqq 0 \\
x_{0}=\varphi & \varphi \in C .
\end{array}
$$

Notice that $S(b)$ is a special case of $U(b) \varphi \equiv y_{b}(\phi)$ where $y(\varphi)(t)$ is the solution of Equation (1) for the initial function $\phi \in C$. That is, the mapping $S(b)$ is $U(b)$ when $F \equiv 0$. Also, if the semigroup $T(t)$, $t \geqq 0$ is compact for $t>0$, we have that $U(b)$ is compact and therefore $S(b)$ is compact.

We also have need to consider the system

$$
\begin{array}{ll}
z(t)=\int_{0}^{t} T(t-s) F\left(y_{s}(\varphi)\right) d s & 0 \leqq t \leqq b \\
z \equiv 0 & \text { on }[-r, 0]
\end{array}
$$

where $y(\varphi)(t)$ is the solution of Equation (1) for the initial function $\phi \in C$.

Proposition 1. Let $F$ satisfy condition (2).

(a) Suppose $(M+N)^{-1}$ exists with the range $R((U(b)-I))$ of $U(b)-I$ contained in $D\left((M+N)^{-1}\right)$, that $\left\|(M+N)^{-1} N(U(b)-I)\right\|_{\text {Lip }}<1$ $(b>r)$ and $\psi \in D\left((M+N)^{-1}\right)$, then solutions of Equation (1) (*) exist and are unique.

(b) Suppose $(M+N S(b))^{-1}$ exists with $R(N(U(b)-S(b))) \subset$ $D\left((M+N S(b))^{-1}\right)$ and $\left\|(M+N S(b))^{-1} N(U(b)-S(b))\right\|_{\text {Lip }}<1 \quad(b>r)$, then solutions of Equation (1) $\left(^{*}\right)$ exist and are unique.

Proof. For an initial function $\varphi \in C$ and its corresponding unique solution of Equation (1) we have

$$
M y_{0}+M y_{b}=M \varphi+N U(b) \varphi=(M+N U(b)) \varphi .
$$

Therefore, in order to solve the boundary value problem Equation (1) $\left(^{*}\right)$ we must solve the operator equation

$$
(M+N U(b)) \varphi=\psi \text {. }
$$

In case (a) we can write Equation (6) in the form

$$
(M+N+N(U(b)-I)) \varphi=\psi
$$

and in case (b) in the form

$$
(M+N S(b)+N(U(b)-S(b))) \varphi=\psi .
$$

Since $(M+N)^{-1}$ exists in (a) and $(M+N S(b))^{-1}$ exists in (b) the above equations become 


$$
\left(I+(M+N)^{-1} N(U(b)-I)\right) \varphi=(M+N)^{-1} \psi,
$$

and

$$
\left(I+(M+N S(b))^{-1} N(U(b)-S(b))\right) \varphi=(M+N S(b))^{-} \psi
$$

when $\psi \in D\left((M+N)^{-1}\right)$ or $\psi \in D\left((M+N S(b))^{-1}\right)$. The equations (9) and $\left(9^{\prime}\right)$ are in the form $x+S x=y$ with $\|S\|_{\text {Lip }}<1$ and so are uniquely solvable.

Given an initial function $\varphi \in C$ and the solution $y(\varphi)(t)$ of Equation (1) we can write

$$
\begin{aligned}
& y(\varphi)(t)=x(\varphi)(t)+z(0)(t) \\
& y_{t}(\varphi)=x_{t}(\varphi)+z_{t}(0)
\end{aligned} \quad 0 \leqq t \leqq b
$$

where $x(\varphi)(t)$ and $z(0)(t)$ are solutions of Equations (7) and (8), respectively. Using the identity (10) we have the following corollary to Proposition $1(b)$.

Corollary to Proposition 1(b). If operator $(M+N S(b))^{-1}$ exists on $C$ and $\left\|(M+N S(b))^{-1} N\right\| e^{(L+\omega) b}<1(b>r)$, then the boundary value problem Equation (1) $\left(^{*}\right)$ has a unique solution.

Proof. We show that the mapping $(M+N S(b))^{-1} N(U(b)-S(b))$ is a strict contraction:

$$
\begin{aligned}
& \left\|(M+N S(b))^{-1} N(U(b)-S(b)) \varphi-(M+N S(b))^{-1}(U(b)-S(b)) \bar{\varphi}\right\|_{c} \\
& \quad \leqq\left\|(M+N S(b))^{-1} N\right\| \sup _{-r \leqq \theta \leqq 0}\left\|\int_{0}^{b+\theta} T(b+\theta-s)\left(F\left(y_{s}(\varphi)\right)-F\left(y_{s}(\bar{\varphi})\right)\right) d s\right\| \\
& \quad \leqq\left\|(M+N S(b))^{-1} N\right\| L e^{\omega b}\|\varphi-\bar{\varphi}\|_{c} \int_{0}^{b} e^{L S} d s \\
& \quad<\left\|(M+N S(b))^{-1} N\right\| e^{(\omega+L) b}\|\varphi-\bar{\varphi}\|_{c}<\|\varphi-\bar{\varphi}\|_{c},
\end{aligned}
$$

for all $\varphi, \bar{\varphi} \in C$.

The result now follows by Proposition 1(b).

Proposition 2. Let $F$ satisfy condition (2). If the mapping $M^{-1}$ exists on $C$ with $\left\|M^{-1} N\right\| e^{(L+\omega) b}<1(b>r)$, then Equation (1) (*) has a unique solution.

Proof. For an initial function $\varphi \in C$ and its corresponding solution $y(\varphi)(t)$ of Equation (1), we have $M y_{0}+N y_{b}=(M+N U(b)) \varphi$. Thus, for the equation $(M+N U(b)) \varphi=\psi, \psi \in C$, we can write $\left(I+M^{-1} N U(b)\right) \varphi=M^{-1} \psi$. From (4) we have that

$$
\begin{aligned}
\left\|M^{-1} N U(b) \varphi-M^{-1} N U(b) \bar{\varphi}\right\|_{c} & \leqq\left\|M^{-1} N\right\|\|U(b) \varphi-U(b) \bar{\varphi}\|_{C} \\
& \leqq\left\|M^{-1} N\right\| e^{(L+\omega) b}\|\varphi-\bar{\varphi}\|_{C}<\|\varphi-\bar{\varphi}\|_{C}
\end{aligned}
$$


for all $\varphi, \bar{\varphi} \in C$. The mapping $M^{-1} N U(b)$ is a strict contraction and so the equation $\left(I+M^{-1} N U(b)\right) \varphi=M^{-1} \psi$ has a unique solution for each $\psi \in C$. The result easily follows.

Using the identity (10) we are able to extend a result found in [9].

Proposition 3. The two point boundary value problem Equation (1) (*) has a solution if and only if $N z_{b}(0) \in \psi+R(M+N S(b))$, $\psi \in C, b>r$.

Proof. Given an initial function $\varphi \in C$, and its corresponding solution $y(\varphi)(t)$ of Equation (1) we have by (10) that

$$
M y_{0}(\varphi)+N y_{b}(\varphi)=M \varphi+N\left(x_{b}(\varphi)+z_{b}(0)\right)=(M+N S(b)) \varphi+N z_{b}(0) \text {. }
$$

If $\psi \in C$ and $M y_{0}(\varphi)+N y_{b}(\varphi)=\psi$, we obtain $\psi=(M+N S(b)) \varphi+$ $N z_{b}(0)$; this gives $N z_{b}(0)=\psi-(M+N S(b)) \varphi$ and so $N z_{b}(0) \in \psi+$ $R(M+N S(b))$.

If there exists a solution $\phi$ of $N z_{b}(0)=\phi+R(M+N S(b)) \varphi$, define $v=-\varphi$. Then for the solution $y(v)(t)$ of Equation (1) we have

$$
\begin{aligned}
M y_{0}(v)+N y_{b}(v) & =M v+N x_{b}(v)+N z_{b}(0) \\
& =(M+N S(b)) v+N z_{b}(0) \\
& =-(M+N S(b)) \varphi+N z_{b}(0)=\psi .
\end{aligned}
$$

Therefore the boundary value problem is solved.

The following result is due to A. Granas [3].

Proposition 4. If $T$ is a compact operator mapping the Banach

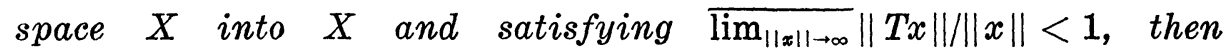
$R(I-T)=X$.

Proposition 4. (i) Suppose the semigroup $T(t), t \geqq 0$ is compact, (ii) $F$ takes closed bounded sets of $C$ into bounded sets in $B$, and $\lim _{\|\varphi\|_{C} \rightarrow \infty}\|F(\varphi)\| /\|\varphi\|_{c}=0$, (iii) there exist unique solutions to the initial value problem Equation (1), $(M+N S(b))^{-1}(b>r)$ exists on $C$ as a bounded operator. Then the boundary value problem Equation (1) (*) has a solution.

Proof. Condition (ii) implies that there exists $K_{1}$ and $K_{2}$ such that $\|F(\varphi)\| \leqq K_{1}\|\varphi\|_{C}+K_{2}$ for all $\varphi \in C$, so that global solutions for Equation (1) exist [2]. Furthermore, we can find constants $\bar{K}_{1}$ and $\bar{K}_{2}$ such that condition (5) is true. Let $\varphi_{n}$ be a sequence of functions in $C$ such that $\left\|\varphi_{n}\right\|_{C} \rightarrow \infty$ as $n \rightarrow \infty$ and define $\beta_{n}=$ $\sup _{0 \leqq t \leqq b}\left\|y_{t}\left(\varphi_{n}\right)\right\|_{c}$. Note that $\beta_{n} \leqq \bar{K}_{1}\left\|\varphi_{n}\right\|_{c}+\bar{K}_{2}$ for each $n$. Let $\varepsilon$ 
be such that $0<\varepsilon<1 / b \bar{K}_{1} e^{\omega b}\left\|(M+N S(b))^{-1} N\right\|$, then by (ii) there exists $h>0$ such that if $\|\varphi\|_{c}>h,\|F \varphi\| \leqq \varepsilon\|\varphi\|_{c}$. We define $R=$ $\max \left\{\|F(\varphi)\|:\|\varphi\|_{C} \leqq h\right\}$ then

$$
\begin{aligned}
\|(M & +N S(b))^{-1} N(U(b)-S(b)) \varphi_{n} \| \\
& \leqq \sup _{-r \leqq \theta \leqq 0}\left\|(M+N S(b))^{-1} N\right\| \int_{0}^{b}\|T(b+\theta-s)\|\left\|F\left(y_{s}\left(\varphi_{n}\right)\right)\right\| d s \\
& \leqq\left\|(M+N S(b))^{-1} N\right\| e^{\omega b} \int_{0}^{b}\left\|F\left(y_{s}\left(\varphi_{n}\right)\right)\right\| d s \\
& \leqq\left\|(M+N S(b))^{-1} N\right\| e^{\omega b} b \max \left\{R, \varepsilon\left(\bar{K}_{1}\left\|\varphi_{n}\right\|_{c}+\bar{K}_{2}\right)\right\} .
\end{aligned}
$$

If $\beta_{n} \rightarrow \infty$ as $n \rightarrow \infty$, we have $\varlimsup_{n \rightarrow \infty} \|(M+N S(b))^{-1} N(U(b)-$ $S(b)) \varphi_{n}\left\|_{c} /\right\| \varphi_{n} \|_{c}<1$ and if $\beta_{n}$ bounded as $n \rightarrow \infty$ then $\varlimsup_{\lim _{n \rightarrow \infty}} \|(M+$ $N S(b))^{-1} N(U(b)-S(b)) \varphi_{n}\|/\| \varphi_{n} \|_{c}=0$. Notice that $U(b)$ exists by (iii) and that by (i) $(M+N S(b)) N(U(b)-S(b))$ is compact. Thus by Proposition A there is a solution to $\left(I+(M+N S(b))^{-1} N(U(b)-S(b))\right) \varphi=$ $(M+N S(b))^{-1} \psi$ and the proposition is proved.

To prove Proposition 5 we need the following result of $Z$. Nashed and J. S. W. Wong [5].

Proposition B. If $A_{1}$ is a strict contraction on a Banach space $X$, i.e., $\left\|A_{1} x-A_{1} y\right\| \leqq \gamma\|x-y\|(0<\gamma<1), x, y \in X$, and $A_{2}$ is a compact mapping on $X$ such that $\lim _{\|x\| \rightarrow \infty}\left\|A_{2} x\right\| /\|x\|=\beta<1-\gamma$, then $R\left(I-\left(A_{1}+A_{2}\right)\right)=X$.

Proposition 5. (i) If the semigroup $T(t), t \geqq 0$ is compact for $t>0$, (ii) $F$ takes closed bounded sets of $C$ into bounded sets in $B$, and $\lim _{\|\theta\|_{C} \rightarrow \infty}\|F(\varphi)\| /\|\varphi\|=0$, (iii) there exist unique solutions to the initial value problem Equation (1), (iv) $M^{-1}$ exists on $C$ as a bounded operator and $\left\|M^{-1} N\right\| e^{j b b}<1(b>r)$. Then the boundary value problem Equation (1) (*) has a solution.

Proof. Given an initial function $\varphi \in C$, we can write

$$
y_{b}(\varphi)(\theta)=T(b+\theta) \varphi(0)+\int_{0}^{b+\theta} T(b+\theta-s) F\left(y_{s}(\varphi)\right) d s
$$

where $y(\varphi)(t)$ is the solution of Equation (1) corresponding to $\varphi$. Define the operators $A_{1}$ and $A_{2}$ on $C$ as follows:

$$
\left(A_{1} \varphi\right)(\theta)=T(b+\theta) \varphi(0) \text { and }\left(A_{2} \varphi\right)(\theta)=\int_{0}^{b+\theta} T(b+\theta-s) F\left(y_{s}(\varphi)\right) d s .
$$

The operator $A_{2}$ is compact by (i) and for $\varphi, \bar{\varphi} \in C$ we have

$$
\left\|M^{-1} N A_{1} \varphi-M^{-1} N A_{1} \bar{\varphi}\right\|_{C} \leqq\left\|M^{-1} N\right\| e^{\omega b b}\|\varphi-\bar{\varphi}\|_{c} \text {. }
$$


By (iv) the operator $M^{-1} N A_{1}$ is Lipschitz with Lipschitz constant $\gamma \leqq\left\|M^{-1} N\right\| e^{\omega \omega b}<1$.

Let $\varphi_{n} \in C$ such that $\left\|\varphi_{n}\right\|_{C} \rightarrow \infty$ as $n \rightarrow \infty$ and define $\beta_{n}=$ $\sup _{0 \leqq t \leq b}\left\|y_{t}\left(\varphi_{n}\right)\right\|_{c}$. As in the proof of Proposition 4 we have constants $K_{1}, \quad K_{2}, \quad \bar{K}_{1}, \quad \bar{K}_{2}$ such that $\|F(\varphi)\| \leqq K_{1}\|\varphi\|_{c}+K_{2}$ and $\left\|y_{t}(\varphi)\right\|_{c} \leqq$ $\bar{K}_{1}\|\varphi\|_{C}+\bar{K}_{2}$; therefore, we have $\beta_{n} \leqq \bar{K}_{1}\left\|\varphi_{n}\right\|_{c}+\bar{K}_{2}$. If the sequence $\beta_{n}$ has limit infinity as $n$ approaches infinity, then by (ii)

$$
\begin{aligned}
\varlimsup_{n \rightarrow \infty}\left\|M^{-1} N A_{2} \varphi_{n}\right\|_{c} /\left\|\varphi_{n}\right\|_{c} & \leqq \varlimsup_{n \rightarrow \infty}\left\|M^{-1} N\right\| e^{\omega b} \varepsilon \int_{0}^{b}\left(\bar{K}_{1}\left\|\varphi_{n}\right\|_{c}+\bar{K}_{2}\right) d s /\left\|\varphi_{n}\right\|_{c} \\
& \leqq\left\|M^{-1} N\right\| e^{\omega \omega b} \varepsilon b \in \bar{K}_{1},
\end{aligned}
$$

where $\varepsilon>0$ is arbitrary. Thus if we choose $\varepsilon<1-\gamma /\left\|M^{-1} N\right\| e^{\prime \prime b} b \bar{K}_{1}$, then $\overline{\lim }_{n \rightarrow \infty}\left\|M^{-1} N A_{2} \varphi_{n}\right\|\left\|_{C} /\right\| \varphi_{n} \|_{C}<1-\gamma$. If the sequence $\beta_{n}$ is bounded, then $\varlimsup_{n \rightarrow \infty}\left\|M^{-1} N A_{2} \varphi_{n}\right\|\left\|_{C} /\right\| \varphi_{n} \|_{C}=0<1-\gamma$. Applying Proposition B, we see that for each $\psi \in C$ there exists a solution $\varphi$ of

$$
\left(I+M^{-1} N\left(A_{1}+A_{2}\right)\right) \varphi=M^{-1} \dot{\psi} .
$$

From the above equation we can solve the boundary value problem Equation (1) $\left(^{*}\right)$.

To illustrate our results we consider the partial functional differential equation

$$
\begin{array}{ll}
w_{t}(x, t)=w_{x x}(x, t)+f(w(x, t-r)) & 0 \leqq t \leqq b \quad 0 \leqq x \leqq l \\
w(0, t)=w(l, t)=0 & t \geqq 0 .
\end{array}
$$

Here $f$ is a real-valued, Lipschitz continuous and continuously differentiable function. We let $B=L_{2}[0, l]$, and define $A$ and $F$ respectively as:

$A: D(A) \rightarrow B$ by $A u=\ddot{u}, D(A)=\{u \in B \mid u$ and $\dot{u}$ are absolutely continuous, $\ddot{u} \in B$ and $u(0)=u(l)=0\}$ and $F: C \rightarrow B$ by $F(\varphi)(x)=$ $f(\varphi(-r)(x)) \varphi \in C$ and $x \in[0, l]$. It is known that $A$ generates a strongly continuous semigroup $T(t), t \geqq 0$ such that $T(t)$ is compact for $t>0$ and $w=0$, see A. Pazy [6, pages 9 and 47]. The function $F$ is Lipschitz continuous and continuously differentiable.

If we let $M=I, N=1 / 4 I$, then $(M+N)^{-1}=4 / 5 I$ and

$$
\begin{aligned}
& \left\|(M+N)^{-1} N(U(b)-I) \varphi-(M+N)^{-1} N(U(b)-I) \bar{\varphi}\right\|_{C} \\
& \quad \leqq\left\|(M+N)^{-1} N\right\|\left(\|U(b) \varphi-U(b) \bar{\varphi}\|_{C}+\|\varphi-\bar{\varphi}\|_{C}\right) \\
& \quad \leqq 1 / 5\left(\left\|y_{b}(\varphi)-y_{b}(\bar{\varphi})\right\|_{c}+\|\varphi-\varphi\|_{C}\right) \leqq 1 / 5\left(e^{L b}\|\varphi-\bar{\varphi}\|_{c}+\|\varphi-\varphi\|_{C}\right) \\
& \quad \leqq 1 / 5\left(e^{L b}+1\right)\|\phi-\bar{\varphi}\|_{c} .
\end{aligned}
$$

Part (a) of Proposition 1 is applicable if $1 / 5\left(e^{L b}+1\right)<1$. This is true if $L b<\ln 4$. 
If the operators $M=I$ and $N=-1 / 4 I$ then

$$
\begin{aligned}
\| M & +N S(b) \varphi\left\|_{C}=\sup _{-r \leqq v \leqq 0}\right\|(M+N S(b) \varphi)(\theta) \| \\
& =\sup _{-r \leqq y \leqq 0}\|\varphi(\theta)-1 / 4 T(b+\theta) \varphi(0)\| \\
& \geqq \sup _{-r \leqq \theta \leqq 0}\|\varphi(\theta)\|-1 / 4\|\varphi(0)\| \geqq\|\varphi\|_{C}-1 / 4\|\varphi\|_{C}=3 / 4\|\varphi\|_{C} .
\end{aligned}
$$

The above estimate implies that $(M+N S(b))^{-1}$ exists on $C$ and $\left\|(M+N S(b))^{-1}\right\| \leqq 4 / 3$, furthermore

$$
\begin{aligned}
\|(M & +N S(b))^{-1} N(U(b)-S(b)) \varphi-(M+N S(b))^{-1} N(U(b)-S(b)) \bar{\varphi} \|_{c} \\
& \leqq\left\|(M+N S(b))^{-1} N\right\|\|(U(b)-S(b)) \varphi-(U(b)-S(b)) \bar{\varphi}\|_{c} \\
& \leqq\left\|(M+N S(b))^{-1} N\right\| e^{L b}\|\varphi-\bar{\varphi}\|_{c} \leqq 4 / 3 \cdot 1 / 4 e^{L b}\|\varphi-\bar{\varphi}\|_{c} \\
& =1 / 3 e^{L b}\|\varphi-\bar{\varphi}\|_{c} .
\end{aligned}
$$

Here if $L b<\ln 3$ then $1 / 3 e^{L b}<1$, and the corollary to Proposition 1 (b) applies.

If $M=I$ and $N=-1 / 2 I$ Proposition 1 is not readily applicable since we can obtain only the following estimate:

$$
\left\|(M+N)^{-1} N(U(b)-I)\right\|_{\text {Lip }} \leqq\left\|(M+N)^{-1} N\right\|\left(e^{L b}+1\right) \leqq e^{L b}+1 .
$$

The term $e^{L b}+1$ cannot be less than 1 for any positive numbers $L$ and $b$. Similarly we have

$$
\left\|(M+N S(b))^{-1} N(U(b)-S(b))\right\|_{\text {Lip }} \leqq\left\|(M+N S(b))^{-1} N\right\| e^{L b} \leqq e^{L b}
$$

and $e^{L b}$ cannot be less than 1 and positive for any $L$ and $b$. Proposition 2, however, is easily applied since $\left\|M^{-1} N\right\| e^{L b}=1 / 2 e^{L b}<1$ if $0<L b<\ln 2$.

If we define $F(\varphi)(x)=f(\varphi(-r)(x))=\varphi^{1 / 4}(-r)(x)$, then

$$
\begin{aligned}
\|F(\varphi)\| /\|\varphi\|_{c} & =\left(\int_{0}^{l}\left|\varphi^{1 / 2}(-r)(x)\right| d x\right)^{1 / 2} / \sup _{-r \leqq \theta \leqq 0} \int_{0}^{l} \varphi^{2}(\theta)(x) \mid d x \\
& \leqq l^{3 / 8}\left(\int_{0}^{l}\left|\varphi^{2}(-r)(x)\right| d x\right)^{1 / 8} / \sup _{-r \leqq \theta \leqq 0} \int_{0}^{l}\left|\varphi^{2}(\theta)(x)\right| d x \\
& \leqq l^{3 / 8}\left(\sup _{-r \leqq \theta \leqq 0} \int_{0}^{l}\left|\varphi^{2}(\theta)(x)\right| d x\right)^{1 / 8} / \sup _{-r \leqq \theta \leqq 0} \int_{0}^{l}\left|\varphi^{2}(\theta)(x)\right| d x
\end{aligned}
$$

and $\lim _{\|\varphi\|_{C \rightarrow \infty}}\|F(\varphi)\| /\|\varphi\|=0$. Furthermore, $F$ takes closed bounded sets of $C$ into bounded sets of $B=L_{2}[0, l]$. Letting $M=I$ and $N=-1 / 4 I$, both $(M+N S(b))^{-1}$ and $M^{-1}$ exist, and Propositions 4 and 5 can be applied to obtain solutions of

$$
\begin{aligned}
& y(t)=T(t) \varphi(0)+\int_{0}^{t} T(t+\theta-s) y_{s}^{1 / 4}(-r)(\cdot) d s \\
& M y_{0}+N y_{b}=\psi \quad b>r .
\end{aligned}
$$


Notice that the length of the interval $b$ does not enter into the discussion for the above example, other than $b$ is required to be greater than $r$.

The next theorem handles periodic boundary conditions, i.e., the boundary condition $y_{0}=y_{b}$.

Proposition 6. Suppose $F$ satisfies condition (2). If the operator $M+N S(b)$ has a bounded inverse defined on $C$ such that $\left\|(M+N S(b))^{-1}\right\|<d$ for some $d>0$ and for all $(r, \gamma)$ where $\gamma$ satisfies $\gamma>r$ and $d\|N\| e^{(L+\omega) r}=1$, then the boundary value problem Equation (1) (*) has a unique solution.

Proof. For a function $\psi \in C$ define the mapping $H: C \rightarrow C$ by

$$
H \varphi=(M+N S(b))^{-1} \psi-(M+N S(b))^{-1} N(U(b)-S(b)) \varphi .
$$

We have for $\varphi, \bar{\varphi} \in C$

$$
\begin{aligned}
&\|H \varphi-H \bar{\varphi}\|_{c}=\|(M+N S(b))^{-1} N(U(b)-S(b)) \varphi \\
&-(M+N S(b))^{-1} N(U(b)-S(b)) \bar{\varphi} \|_{c} \\
& \leqq\left\|(M+N S(b))^{-1} N\right\|\left\|z_{b}(\varphi)-\bar{z}_{b}(\bar{\varphi})\right\|_{c} \\
& \leqq d\|N\| \sup _{-r \leqq \theta \leqq 0}\|z(\varphi)(b+\theta)-\bar{z}(\bar{\varphi})(b+\theta)\| \\
& \leqq d\|N\| \int_{0}^{b} e^{(v(b-s)}\left\|F\left(y_{s}(\varphi)\right)-F\left(y_{s}(\bar{\varphi})\right)\right\| d s \\
& \leqq d\|N\| e^{(\omega b} L \int_{0}^{b} e^{-(\omega}\left\|y_{s}(\varphi)-y_{s}(\bar{\varphi})\right\|_{c} d s \\
& \leqq d\|N\| e^{(L+\omega) b} L b\|\varphi-\bar{\varphi}\|_{c} .
\end{aligned}
$$

The operator $H$ is a contraction if $b$ is sufficiently small and the boundary value problem is uniquely solvable.

REMARK. Proposition 4 also handles periodic boundary conditions since again the only requirement on $M$ and $N$ is the existence of $(M+N S(b))^{-1}$. The inverse of $M+N S(b)$ exists with domain $C$ if and only if the boundary value problem Equation $(7)\left({ }^{*}\right)$ has a unique solution for each $\psi \in C$.

Acknowledgment. The author would like to thank Professor Glenn F. Webb for several helpful conversations.

\section{REFERENCES}

1. R. Fennell and P. Waltman, $A$ boundary value problem for a system of nonlinear functional differential equations, J. Math. Anal., 26 (1969), 447-453.

2. W. E. Fitzgibbon, Semilinear Functional Differential Equations in Banach Space, J. Differential Equations, 29 (1978), 1-14. 
3. A. Granas, The theory of compact vector fields and some of its applications to topology and functional spaces, I. Rozprowy Mat., 30 (1962), 93.

4. J. K. Hale, Functional Differential Equations, Springer-Verlag, New York, 1971.

5. M. Z. Nashed and J. S. W. Wong, Some variants of a fixed point theorem of Krasnoselskii and applications to nonlinear integral equations, J. Math. Mech., 18 (1969), 767-777.

6. A. Pazy, Semigroups of Linear Operators and Applications to Partial Differential Equations, Lecture Notes \#10, University of Maryland, College Park, Maryland, 1974.

7. G. W. Reddien and G. F. Webb, Boundary value problems for functional differential equations with $L^{2}$ initial functions, to appear.

8. C. Travis and G. Webb, Existence and stability for partial functional differential equations, Trans. Amer. Math. Soc., 200 (1974), 395-418.

9. P. Waltman ann J.S. W. Wong, Two point boundary value problems for nonlinear functional differential equations, Trans. Amer. Math. Soc., 164 (1972), 39-54.

Received June 8, 1977 and in revised form October 18, 1978.

WEST VIRGINIA UNIVERSITY

Morgantown, WV 26505 


\section{PACIFIC JOURNAL OF MATHEMATICS}

\section{EDITORS}

DONALD BABBITT (Managing Editor)

University of California

Los Angeles, CA 90024

Hugo RossI

University of Utah

Salt Lake City, UT 84112

C. C. MOORE and ANDREW OGG

University of California

Berkeley, CA 94720

\section{J. DugunduI}

Department of Mathematics

University of Southern California

Los Angeles, CA 90007

R. Finn and J. Milgram

Stanford University

Stanford, CA 94305

\section{ASSOCIATE EDITORS}
E. F. BeCKenBACH
B. H. NeumanN
F. WOLF
K. YosHIDA

\section{SUPPORTING INSTITUTIONS}

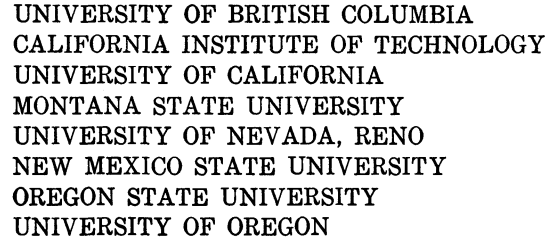

UNIVERSITY OF BRITISH COLUMBIA CALIFORNIA INSTITUTE OF TECHNOLOGY UNIVERSITY OF CALIFORNIA

MONTANA STATE UNIVERSITY

UNIVERSITY OF NEVADA, RENO

NEW MEXICO STATE UNIVERSITY

OREGON STATE UNIVERSITY UNIVERSITY OF OREGON

\author{
UNIVERSITY OF SOUTHERN CALIFORNIA \\ STANFORD UNIVERSITY \\ UNIVERSITY OF HAWAII \\ UNIVERSITY OF TOKYO \\ UNIVERSITY OF UTAH \\ WASHINGTON STATE UNIVERSITY \\ UNIVERSITY OF WASHINGTON
}

The Supporting Institutions listed above contribute to the cost of publication of this Journal, but they are not owners or publishers and have no responsibility for its content or policies.

Mathematical papers intended for publication in the Pacific Journal of Mathematics should be in typed form or offset-reproduced, (not dittoed), double spaced with large margins. Please do not use built up fractions in the text of the manuscript. However, you may use them in the displayed equations. Underline Greek letters in red, German in green, and script in blue. The first paragraph or two must be capable of being used separately as a synopsis of the entire paper. Please propose a heading for the odd numbered pages of less than 35 characters. Manuscripts, in triplicate, may be sent to any one of the editors. Please classify according to the scheme of Math. Reviews, Index to Vol. 39. Supply name and address of author to whom proofs should be sent. All other communications should be addressed to the managing editor, or Elaine Barth, University of California, Los Angeles, California, 90024.

50 reprints to each author are provided free for each article, only if page charges have been substantially paid. Additional copies may be obtained at cost in multiples of 50 .

The Pacific Journal of Mathematics is issued monthly as of January 1966. Regular subscription rate: $\$ 84.00$ a year (6 Vols., 12 issues). Special rato: $\$ 42.00$ a year to individual members of supporting institutions.

Subscriptions, orders for numbers issued in the last three calendar years, and changes of address shoud be sent to Pacific Journal of Mathematics, P.O. Box 969, Carmel Valley, CA 93924, U.S.A Old back numbers obtainable from Kraus Periodicals Co., Route 100, Millwood, NY 10546.

PUBLISHED BY PACIFIC JOURNAL OF MATHEMATICS, A NON-PROFIT CORPORATION

Printed at Kokusai Bunken Insatsusha (International Academic Printing Co., Ltd.). 8-8, 3-chome, Takadanobaba, Shinjuku-ku, Tokyo 160, Japan.

Copyright (C) 1980 by Pacific Jounal of Mathematics Manufactured and first issued in Japan 


\section{Pacific Journal of Mathematics \\ Vol. 90, No. $2 \quad$ October, 1980}

Frank Hayne Beatrous, Jr., Hölder estimates for the $\bar{\partial}$ equation with a support condition ..................................... 249

Charles L. Belna, Michael Jon Evans and Paul Humke, Planar continua

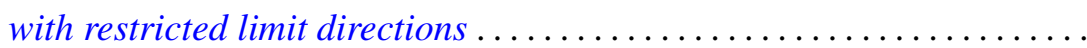

Leon Brown and Takashi Ito, Classes of Banach spaces with unique isometric preduals................................. 261

V. K. Deshpande, Completions of Noetherian hereditary prime rings ..... . 285

Deepak Dhar, Asymptotic enumeration of partially ordered sets . . . . . . . 299

Zeev Ditzian, On interpolation of $L_{p}[a, b]$ and weighted Sobolev

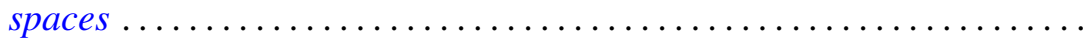

Andrew George Earnest, Congruence conditions on integers represented by

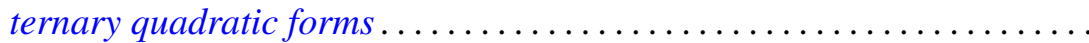

Melvin Faierman, Bounds for the eigenfunctions of a two-parameter system of ordinary differential equations of the second order ..............

Hector O. Fattorini, Vector-valued distributions having a smooth

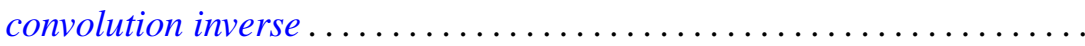

Howard D. Fegan, The spectrum of the Laplacian on forms over a Lie

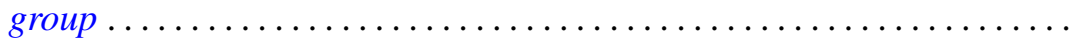

Gerald Leonard Gordon, On the degeneracy of a spectral sequence associated to normal crossings..

S. Madhavan, On bisimple weakly inverse semigroups ... 397

Françoise Mathot, On the decomposition of states of some

Roger McCann, Embedding asymptotically stable dynamical systems into radial flows in $l_{2}$

Michael L. Mihalik, Ends of fundamental groups in shape and proper homotopy...............................

Samuel Murray Rankin, III, Boundary value problems for partial functional differential equations .

Randy Tuler, Arithmetic sums that determine linear characters on $\Gamma(N)$

Jeffrey D. Vaaler, On linear forms and Diophantine approximation ..

G. P. Wene, Alternative rings whose symmetric elements are nilpotent or a right multiple is a symmetric idempotent. . 